\title{
Diagnostic performance of regional cerebral blood flow images derived from dynamic PIB scans in Alzheimer's disease
}

\author{
Débora E. Peretti ${ }^{1}$ D, David Vállez García ${ }^{1 *}$, Fransje E. Reesink², Janine Doorduin ${ }^{1}$, Bauke M. de Jong², \\ Peter P. De Deyn ${ }^{2,3}$, Rudi A. J. O. Dierckx ${ }^{1}$ and Ronald Boellaard ${ }^{1}$
}

\begin{abstract}
Background: In clinical practice, visual assessment of glucose metabolism images is often used for the diagnosis of Alzheimer's disease (AD) through 2-[18 F]-fluoro-2-deoxy-D-glucose (FDG) positron emission tomography (PET) scans. However, visual assessment of the characteristic AD hypometabolic pattern relies on the expertise of the reader. Therefore, user-independent pipelines are preferred to evaluate the images and to classify the subjects. Moreover, glucose consumption is highly correlated with cerebral perfusion. Regional cerebral blood flow (rCBF) images can be derived from dynamic ${ }^{11} \mathrm{C}$-labelled Pittsburgh Compound B PET scans, which are also used for the assessment of the deposition of amyloid- $\beta$ plaques on the brain, a fundamental characteristic of AD. The aim of this study was to explore whether these rCBF PIB images could be used for diagnostic purposes through the PMOD Alzheimer's Discrimination Tool.
\end{abstract}

Results: Both tracer relative cerebral flow $\left(R_{1}\right)$ and early PIB (ePIB) (20-130 s) uptake presented a good correlation when compared to FDG standardized uptake value ratio (SUVR), while ePIB (1-8 min) showed a worse correlation. All receiver operating characteristic curves exhibited a similar shape, with high area under the curve values, and no statistically significant differences were found between curves. However, $R_{1}$ and ePIB (1-8 min) had the highest sensitivity, while FDG SUVR had the highest specificity.

Conclusion: rCBF images were suggested to be a good surrogate for FDG scans for diagnostic purposes considering an adjusted threshold value.

Keywords: Alzheimer's disease, PIB, Relative cerebral blood flow, PALZ

\section{Background}

Positron emission tomography (PET) imaging improves the diagnosis of Alzheimer's disease (AD) due to the broad range of functional processes it assesses [1]. One of the most common radiotracers for PET scans, both in the clinic and in research, is $2-\left[{ }^{18} \mathrm{~F}\right]$-fluoro-2-deoxy-Dglucose (FDG). This radiotracer evaluates the metabolism in the brain by measuring glucose consumption, allowing for the recognition of specific disease patterns. $\mathrm{AD}$ is characterized by a hypometabolic pattern that includes regions such as the precuneus, posterior cingulate

\footnotetext{
* Correspondence: d.vallez-garcia@umcg.nl

'Department of Nuclear Medicine and Molecular Imaging, University Medical Center Groningen, University of Groningen, Hanzeplein 1, 9713, GZ, Groningen, The Netherlands

Full list of author information is available at the end of the article
}

cortex, posterior temporoparietal cortex, and medial temporal lobe [2]. The identification of the hypometabolic pattern caused by the disease is of great importance for clinicians during the diagnostic process. Another advantage of using FDG-PET is that it is sensitive to changes in the early stages of the disease, even in patients without clinical symptoms of dementia [3-5]. However, visual reading of the FDG-PET images relies on the experience of the reader [2,6]. Therefore, different methods of user-independent analyses have been developed to assist in the interpretation of the scans [7-9].

Previous studies have shown a link between glucose consumption and regional cerebral blood flow (rCBF): blood delivery across the brain increases with metabolic demand $[10,11]$. This link might allow the use of rCBF 
images for the classification of AD patients since regions that have the glucose consumption affected might also be hypoperfused. These rCBF images can be derived from standardized uptake value ratio (SUVR) of radiotracers that measure the flow in the brain, such as ${ }^{15} \mathrm{O}$ Water [12], the weighted average of the initial frames of a dynamic scan [13-15], or through pharmacokinetic modelling [16-18].

A radiotracer that is commonly used in AD trials and in the clinic is ${ }^{11} \mathrm{C}$-labeled Pittsburgh Compound B (PIB). PET scans with PIB allow the clinician to assess the deposition of amyloid- $\beta$ (A $\beta)$ plaques in the brain. Therefore, FDG and PIB images provide complementary information that improve the diagnosis of AD $[1,19]$. Yet, dual-tracer studies can be expensive and increase patient discomfort and exposure to radiation $[17,20]$. Hence, the use of a single tracer to assess both $\mathrm{A} \beta$ deposits and the hypometabolism pattern in the brain at the same time would be ideal. In this respect, using both the tracer's binding potential and parametric images of relative tracer flow $\left(R_{1}\right)$ might provide such complementary image information concerning $\mathrm{A} \beta$ deposition and $\mathrm{rCBF}$, respectively.

Since PIB possesses high lipophilicity [21], it meets the prerequisite to provide $\mathrm{rCBF}$ images that might be a good surrogate for FDG. This hypothesis has already been explored in previous studies, which compared FDG scans to PIB images generated through pharmacokinetic modelling [16-18, 22], and a time-weighted average of the first frames of a dynamic PIB scan [13, 22-25].

A commonly known tool for the automated discrimination of $\mathrm{AD}$ patients is PMOD Alzheimer's Discrimination Tool (PALZ). The user provides PALZ with the FDG images of a subject, which is compared to a database of healthy controls. PALZ estimates how different is the metabolism pattern of the provided image from a group of typical healthy subjects [6], and gives a score that helps to determine whether the subject presents an abnormal scan. Although this automated discrimination tool was designed for FDG, rCBF images might provide similar results due to the high correlation between images.

The aim of this study was to explore whether rCBF images, derived from dynamic PIB scans, could be used for the diagnosis of AD using the PALZ tool from PMOD. To this end, $R_{1}$ and summed early frame images were generated and used as input images in PALZ. The results were then compared to the results from the FDG scans. Correlations between scores and new thresholds for classifying $\mathrm{AD}$ patients were drawn for each method.

\section{Material and methods Subjects}

A cohort of fifty-two subjects was drawn from a larger ongoing study at the memory clinic of the University Medical Center Groningen (UMCG), Groningen, The
Netherlands. All subjects gave their written informed consent to participate in the study, which was approved by the Medical Ethical Committee of the UMCG (2014/ $320)$. The study was conducted in agreement with the Declaration of Helsinki and subsequent revisions.

The subjects were first diagnosed by consensus of a multidisciplinary team based on clinical assessment following the guidelines of the National Institute on Aging Alzheimer's Association criteria (NIA-AA) [26] for the $\mathrm{AD}$ patients, and on the Petersen criteria [27] for the MCI patients. Healthy subjects presented no cognitive complaints and a mini-mental state exam score higher than 28. Then, all subjects underwent two PET scans and a T1-3D magnetic resonance imaging (MRI). After this, clinical diagnoses were reconsidered under the $\mathrm{Na}$ tional Institute on Aging and the Alzheimer's Association Research Framework [28]. Subjects were then reclassified as $\mathrm{AD}, \mathrm{MCI}+$ (mild cognitive impairment with $\mathrm{A} \beta$ deposition), $\mathrm{MCI}-$ (mild cognitive impairment or other dementia without $A \beta$ deposition), or healthy controls $(\mathrm{HC})$. Positivity or negativity regarding $A \beta$ deposition was done by consensus of visual inspection by experts. A summary of the demographic characteristics is shown in Table 1.

\section{PET acquisition}

All subjects underwent a static FDG-PET and a dynamic PIB-PET examination. Scans were performed with either a Siemens Biograph $40 \mathrm{mCT}$ or $64 \mathrm{mCT}$ scanner (Siemens Medical Solution, USA). Since both systems are of the same vendor and of the same generation, the acquisition and reconstruction protocols were harmonized, and the calibration of the systems was equally done; no difference between data provided by the different scanners was expected. Nonetheless, a $t$ test comparing the results provided by the different scanners showed that there were no statistically significant differences between them. Patients were in standard resting conditions with eyes closed during the scans. The radiotracers were synthesized at the radiopharmacy facility at the Nuclear Medicine and Molecular Imaging department at the UMCG, according to Good Manufacturing Practice, and were administered via venous cannula. The subjects had both scans performed on the same month, with the FDG taking place at least $90 \mathrm{~min}$ after PIB injection, with the

Table 1 Demographic characteristics of subjects

\begin{tabular}{lllll}
\hline & $\mathrm{AD}(n=15)$ & $\mathrm{MCl}+(n=11)$ & $\mathrm{MCl}-(n=10)$ & $\mathrm{HC}(n=16)$ \\
\hline Sex & & & & \\
Male & 9 & 7 & 8 & 11 \\
Female & 6 & 4 & 2 & 5 \\
Age (years) & $65 \pm 8$ & $65 \pm 5$ & $67 \pm 9$ & $69 \pm 5$ \\
MMSE score & $25 \pm 3$ & $27 \pm 2$ & $24 \pm 7$ & $30 \pm 1$ \\
\hline
\end{tabular}


exception of five subjects, who had a delay of up to 4 months between scans.

The dynamic PIB-PET acquisitions started $10 \mathrm{~s}$ before tracer injection $(375 \pm 50 \mathrm{MBq})$ and lasted at least 60 min (frames: $7 \times 10 \mathrm{~s}, 3 \times 30 \mathrm{~s}, 2 \times 60 \mathrm{~s}, 2 \times 120 \mathrm{~s}, 2 \times 180$ $\mathrm{s}, 5 \times 300 \mathrm{~s}$, and $2 \times 600 \mathrm{~s})$. The static FDG-PET scans were acquired $30 \mathrm{~min}$ after injection $(203 \pm 8)$ and lasted for $20 \mathrm{~min}$. All subjects were fasted for at least $6 \mathrm{~h}$ before injection, and glucose levels in plasma were measured before the scan, and the PET scan was only performed if glucose levels were lower than $7 \mathrm{mmol} / \mathrm{l}$ [29]. All PET images were reconstructed from list-mode data using 3D OSEM (3 iterations and 24 subsets), point spread function correction, and time-of-flight. The resulting images had a matrix of $400 \times 400 \times 111$, with isotropic $2 \mathrm{~mm}$ voxels, and smoothed 2-mm Gaussian filter at full width and half maximum (FWHM).

\section{Image processing}

The PMOD software package (version 3.8; PMOD Technologies LLC) was used for image registration and data analysis. The MRI scans were normalized to the Montreal Neurological Institute (MNI) space using tissue probability maps [30]. The PIB-PET images were first corrected for motion (in case of any) using the averaged first 13 frames as reference and then aligned to the individual MRI. The Hammers atlas [31] was used to draw the volume of interest (VOI) of the grey matter from the cerebellum. All PET images were smoothed using a 6mm Gaussian filter at FWHM, and all voxels outside of the brain were masked.

The $R_{1}$ parametric images were generated by pharmacokinetic modelling on a voxel level of the PIB-PET scans in individual space. The simplified reference tissue model 2 (SRTM2) [32] was chosen for this analysis [33], with the grey matter from the cerebellum as the reference tissue [34-37]. A first estimate of the binding potential $\left(B P_{\mathrm{ND}}\right)$ was done using the simplified reference tissue (SRTM) [38], so the efflux parameter of the reference region $\left(k_{2}{ }^{\prime}\right)$ could be fixed. This parameter was taken as the median value from all voxels with a $B P_{\mathrm{ND}}$ higher than 0.05. Then, SRTM2 was applied with a restriction on the range of the apparent efflux rate constant values, with a minimum of 0.01 and a maximum of 0.03 , and 80 basis functions to generate the final $R_{1}$ parametric maps.

The early-stage PIB (ePIB) distribution images were generated using the time-weighted average of the frames corresponding to the intervals of 20 to $130 \mathrm{~s}$ and 1 to 8 $\mathrm{min}$. These intervals were chosen because previous studies have found that 20 to $130 \mathrm{~s}$ was the best interval to discriminate between patients and healthy subjects [22], and 1 to $8 \mathrm{~min}$ have shown the best correlation with FDG scans [24]. Then, the standardized uptake value ratios (SUVR) were calculated by dividing each voxel of the image by the ratio of the injected dose and body weight of the subject and normalizing to the average value of the reference region (i.e. grey matter of the cerebellum).

To compare with the FDG-PET images, the FDG SUVR images were generated in the same manner as the ePIB SUVR, also using the grey matter of the cerebellum as the reference region.

For each subject, an FDG SUVR, $R_{1}$, ePIB (20-130 s), and ePIB (1-8 $\mathrm{min})$ were generated and evaluated by PALZ (v3.9, PMOD Technologies LLC), which gave a PET $_{\text {SCORE }}$ per image for each method according to how much the regions typically affected by $\mathrm{AD}$ deviated from what is expected of a healthy person. An overview of the steps taken for analysing the images is provided in Additional file 1.

\section{Statistical analysis}

An ANOVA per method was performed to check if the groups presented significantly different $\mathrm{PET}_{\mathrm{SCORES}}$ for each method. Then, a pairwise $t$ test was done to compare the significance between groups within methods. For this test, the $p$ values were adjusted for multiple comparisons using the Holm method [39].

A general linear model was used to explore the relationship between the $\mathrm{PET}_{\text {SCORES }}$ of each PIB-derived image (independent variable) and the FDG SUVR (dependent variable) for all subjects. A $p$ value of 0.05 was used as a significance threshold for all analyses. No correction for multiple comparisons was made.

A Bland-Altman plot was made to evaluate the agreement between the PET SCORE $_{\text {measured by PIB-derived }}$ methods and FDG SUVR. The difference between scores was plotted against the FDG SUVR PET SCORES $_{\text {, since }}$ these scores were considered the reference values [40]. Furthermore, linear regressions were made to assess the bias of each rCBF measure compared to the FDG SUVR PET $_{\text {SCORES. }}$.

Receiver-operating characteristic (ROC) curves were plotted to estimate the sensitivity and specificity of each method using Youden's method [41], using only the $\mathrm{PET}_{\mathrm{SCORE}}$ from the $\mathrm{AD}$ and $\mathrm{HC}$ groups, since PALZ was developed to differentiate AD from healthy subjects, and not between different types of dementia. DeLong's test was applied to find if there was a correlation between the $\mathrm{rCBF}$ and FDG SUVR curves [42]. All results were analysed using RStudio (version 1.1.456, $\mathrm{R}$ version 3.5.1 [43]).

\section{Results}

PET SCORES

In general terms, the FDG SUVR images were in agreement with the pattern expected from the literature 
(Fig. 1), showing a hypometabolic pattern for the $\mathrm{AD}$ group, while the $\mathrm{HC}$ subjects presented no abnormal cortical uptake of the tracers. The resemblance between the $R_{1}$ and ePIB when compared to the FDG SUVR was also notable, with similar AD patterns of decreased flow on the parietal lobe, for example.

The distribution of the $\mathrm{PET}_{\mathrm{SCORES}}$ for each method for all subjects is shown in Fig. 2. In general, all methods presented a statistically significant difference between groups $(p<0.05)$. All methods were also able to differentiate between the $\mathrm{AD}$ and $\mathrm{HC}$ groups, but none of them was capable of distinguishing between $\mathrm{MCI}+$ and $\mathrm{MCI}-$. While the FDG SUVR was able to show a statistically significant difference between the $\mathrm{HC}$ and both $\mathrm{MCI}+$ and MCI- groups, of the rCBF methods, only $R_{1}$ presented a significant difference between the $\mathrm{HC}$ and $\mathrm{MCI}+$ groups. Means, standard deviations, and range of the scores of all groups for all methods can be seen in Additional file 2: Table S2.

\section{Correlation of scores from FDG SUVR, $R_{1}$, and ePIB}

The scatter plots of the scores given to the FDG SUVR images suggest a high correlation with the images provided by the rCBF images (Fig. 3). $R_{1}$ presented a correlation of 0.90 with the FDG SUVR, which was the highest correlation across all rCBF methods. The scores from FDG SUVR were highly predictive of the ones from $R_{1}$, accounting for $81 \%$ of variability $\left(R^{2}=0.81, p<0.001\right.$, intercept $=0.90$, slope $=0.74$ ). The scores from ePIB (20-130 s) also presented a high correlation as compared to the ones from FDG SUVR (0.87), but the predictability of the method was lower, $74 \%\left(R^{2}=0.74, p<0.001\right.$, intercept $=1.20$, slope $=0.71)$. While ePIB $(1-8 \mathrm{~min})$ $\mathrm{PET}_{\mathrm{SCORES}}$ also presented a high correlation as compared to the ones from FDG SUVR, of 0.82, this method was not as predictive as the other two, accounting for $66 \%$ of the variability only $\left(R^{2}=0.66, p<0.001\right.$, intercept $=0.83$, slope $=0.55$ ).

\section{Bias assessment}

The bias found between FDG SUVR and rCBF PETSCORES was monophasic for the $R_{1}$ and ePIB (20-130 s) methods, meaning that, in general, they overestimated the $\mathrm{PET}_{\text {SCORES }}$, of $26 \%$ for the $R_{1}$ (slope $=-0.26$, intercept $=0.9)$, and $29 \%$ for the ePIB (20-130 s) (slope = -0.29 , intercept $=1.20)$. Meanwhile, the ePIB $(1-8 \mathrm{~min})$ method presented a biphasic relationship (slope $=-0.45$, intercept $=0.83$ ): it overestimates the $\mathrm{PET}_{\text {SCORES }}$ of the

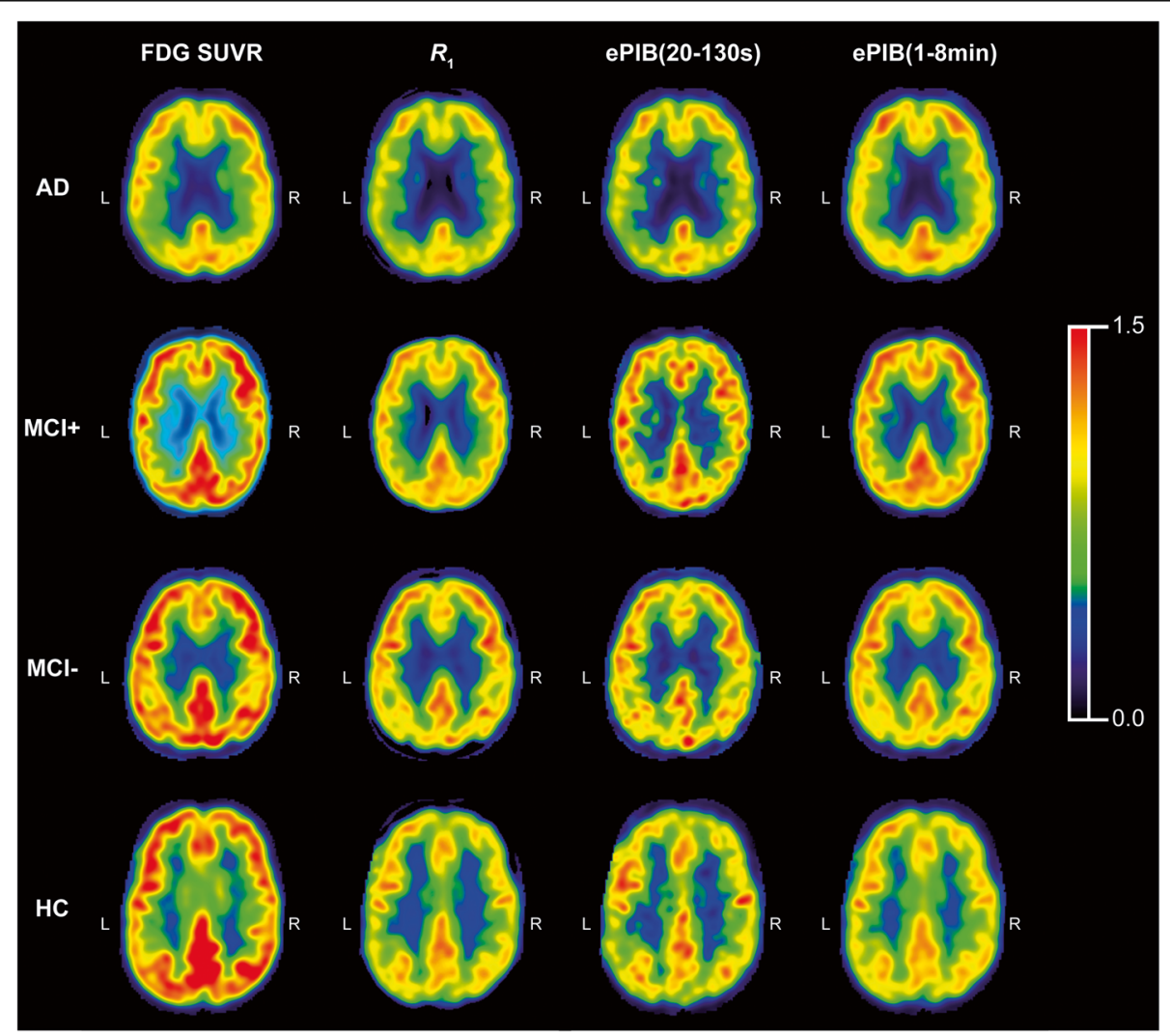

Fig. 1 Representative studies. Transaxial slices of the brain are shown. From left to right: FDG SUVR images, $R_{1}$ parametric maps, ePIB (20-130 s), and ePIB (1-8 min) images. On the first row, images from an AD patient; on the second, an MCl+ subject; on the third, an MCl- subject; and at the bottom, an $\mathrm{HC}$ subject. All colour scales are adjusted to the same range 


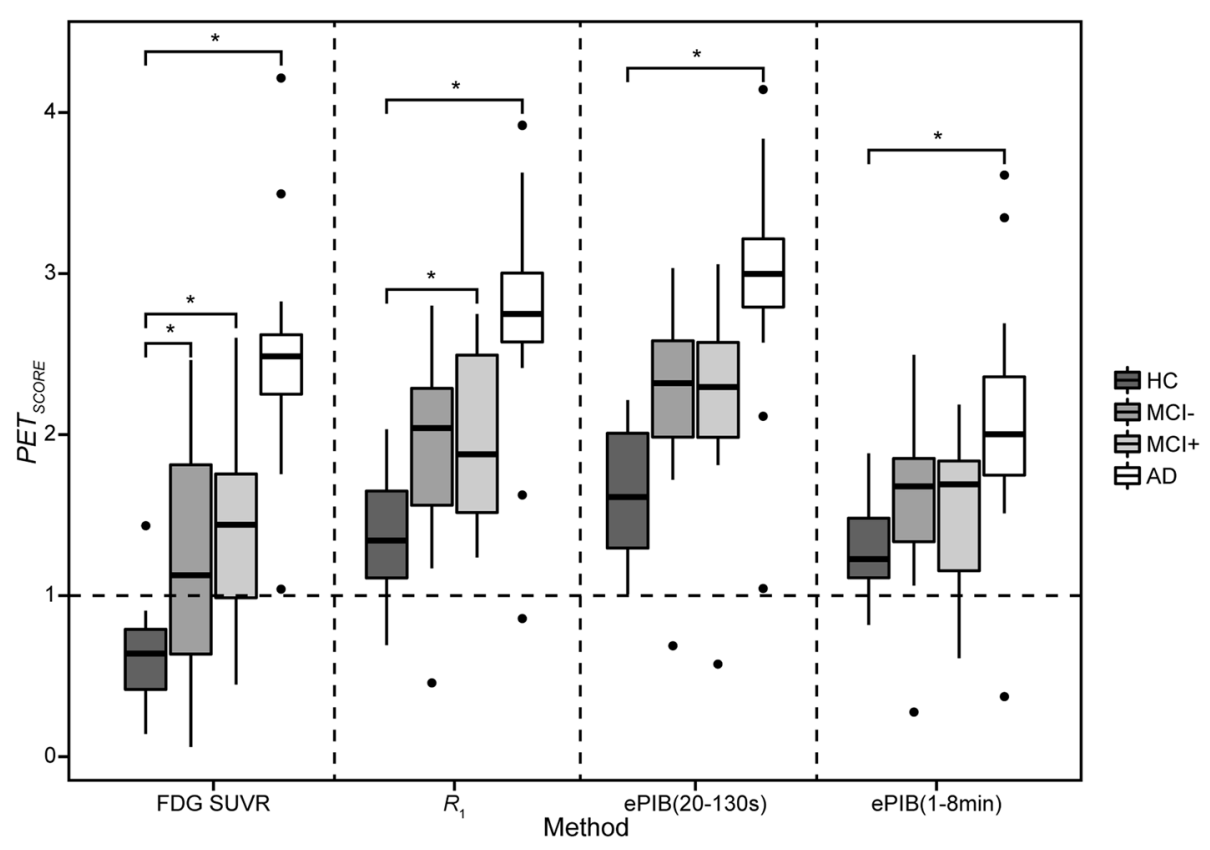

Fig. 2 Distribution of PET $T_{\text {SCORES }}$ per method. Distribution of subjects' PET sCORES from FDG SUVR, $R_{1}$, ePIB (20-130 s), and ePIB (1-8 min) respectively from left to right. Darkest grey boxes represent data from the AD group; dark grey represents $\mathrm{MCl}+$ subjects; light grey represents $\mathrm{MCl}-$; and white represents HC. A dashed line at PET SCORE $=1$ represents the threshold from PALZ for the classification of AD patients. The stars represent the differences between the groups that are statistically significant

HC group by approximately $50 \%$ while underestimating the AD group by nearly $19 \%$. In summary, the $R_{1}$ method presented the smallest bias of all methods and this bias was larger for the $\mathrm{HC}$ subjects than for the $\mathrm{AD}$ patients (Fig. 4) [44, 45].

\section{ROC curves}

With the ROC curves (Fig. 4), it was possible to find a new $\mathrm{PET}_{\text {SCORE }}$ threshold for classifying the subjects as $\mathrm{AD}$ or $\mathrm{HC}$ for each of the rCBF methods. The optimal threshold for the best differentiation of the groups was of 2.22 for the $R_{1}$ method, with a sensitivity of 0.87 and a specificity of 1 . The second highest threshold was 2.08 , from the ePIB (20-130 s) method, with a sensitivity of 0.93 and a specificity of 0.94 . The ePIB (1-8 min) method resulted in a threshold of 1.50 for differentiating the groups, with a sensitivity of 0.93 and a specificity of 0.81 . The ROC curves also showed that the area under the curve was high for all methods, the highest being for the FDG SUVR (0.99), followed by ePIB (20-130 s) (0.94), $R_{1}(0.92)$, and ePIB (1-8 min) (0.89). No statistically significant differences were found between the rCBF and FDG SUVR curves.

\section{Discussion}

The aim of this study was to use rCBF images derived from PIB-PET scans as a surrogate for FDG through an automated discrimination tool. The tool used in this work was PALZ, from PMOD Technologies. PALZ gives the images a $P E T_{\text {SCORE }}$ and classifies the subjects as $A D$ or not based on a threshold of 1. This tool uses FDGPET scans for the diagnosis of the subjects, but since metabolism and blood flow in the brain are highly correlated [10], this tool might also be used to distinguish between groups using rCBF images. Furthermore, the most recent guidelines for $A D$ studies require $A \beta$ imaging for the diagnosis of AD [46]. Therefore, the use of PIBderived $\mathrm{rCBF}$ images in place of FDG scans, since PIB is already used for $A \beta$ imaging, might be of advantage since it reduces costs and patient discomfort and exposure to radiation.

The distribution of the PET $\mathrm{PCORES}_{\text {Showed a clear dis- }}$ tinction between methods, with the FDG SUVR PETSCORES being smaller than the ones from rCBF images, especially for the $\mathrm{HC}$ group (Fig. 2). It can also be seen that FDG SUVR, $R_{1}$, and ePIB (20-130 s) PET SCORES presented a clearer distinction between groups than ePIB (1-8 min). This suggests that ePIB (1-8 min) might not be an optimal method to diagnose patients, as it has already been observed in a previous study [22]. No significant distinction was found between $\mathrm{MCI}+$ and MCI- groups, which was expected since PALZ was not developed to differentiate between diseases, but only to distinguish the $\mathrm{AD}$ patients from the $\mathrm{HC}$ subjects.

Overall, the high correlation between $\mathrm{PET}_{\text {SCORES }}$ provided by different methods indicates that rCBF images 


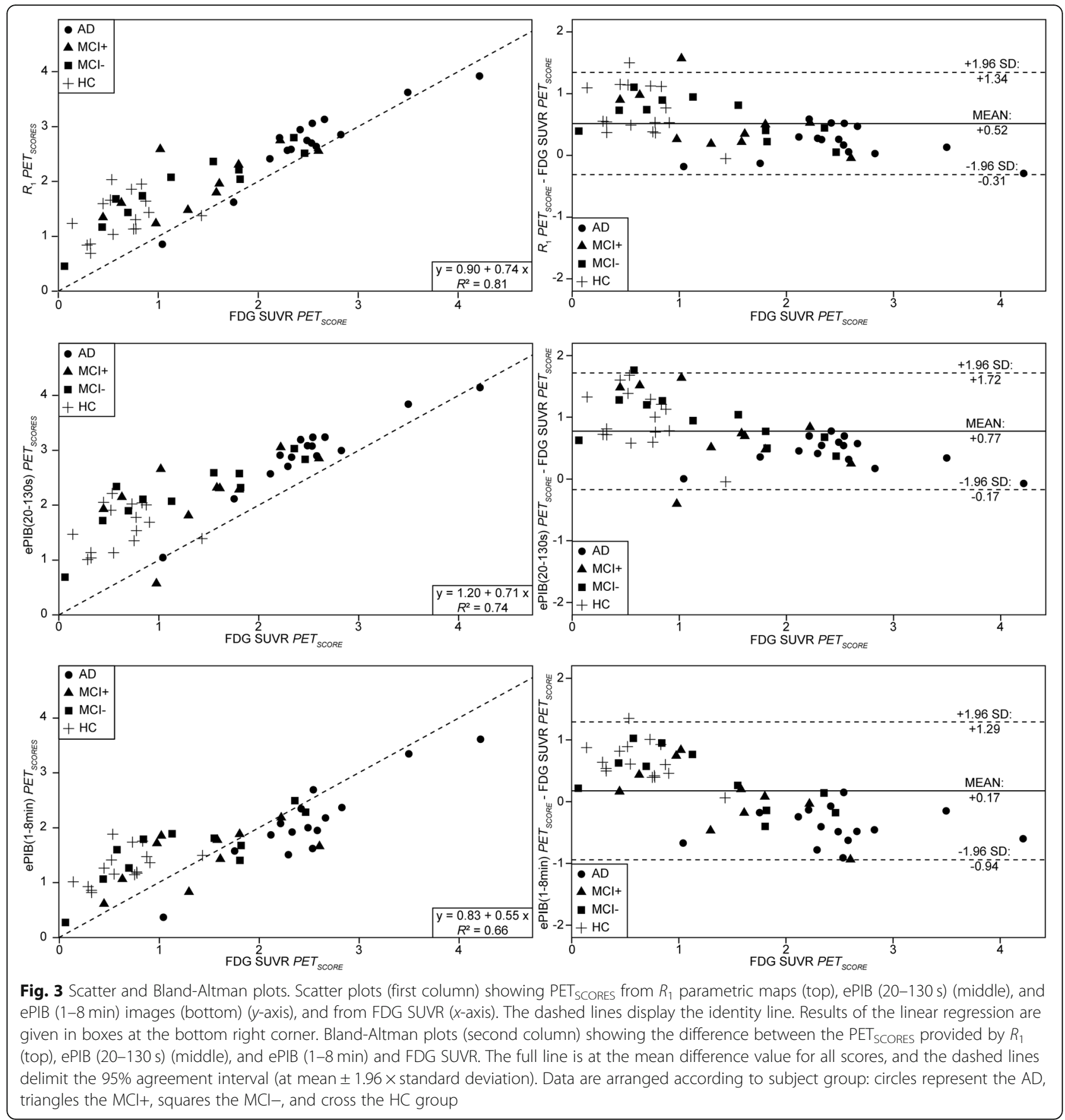

might be a good surrogate to FDG SUVR images. However, the slopes and intercepts of the linear regressions suggest that the threshold should be adjusted depending on the method used to generate the images. Furthermore, the bias between scores was different depending on the group, with a smaller bias for the $\mathrm{AD}$ patients than for the $\mathrm{HC}$ subjects. This difference might be related to the fact that rCBF images have a better correlation with FDG SUVR in patients with more binding of
PIB than in subjects with no specific binding in cortical matter, which is the case for the HC subjects [22].

Moreover, in a comparison of each of the rCBF methods individually with FDG SUVR, $R_{1}$ seemed to outperform both ePIB methods. The higher correlation and small bias from this method lead to the conclusion that the $R_{1}$ images might be the method of preference to substitute FDG-PET scans when an automated tool to differentiate subjects is used, as was suggested by previous studies [22, 23]. 


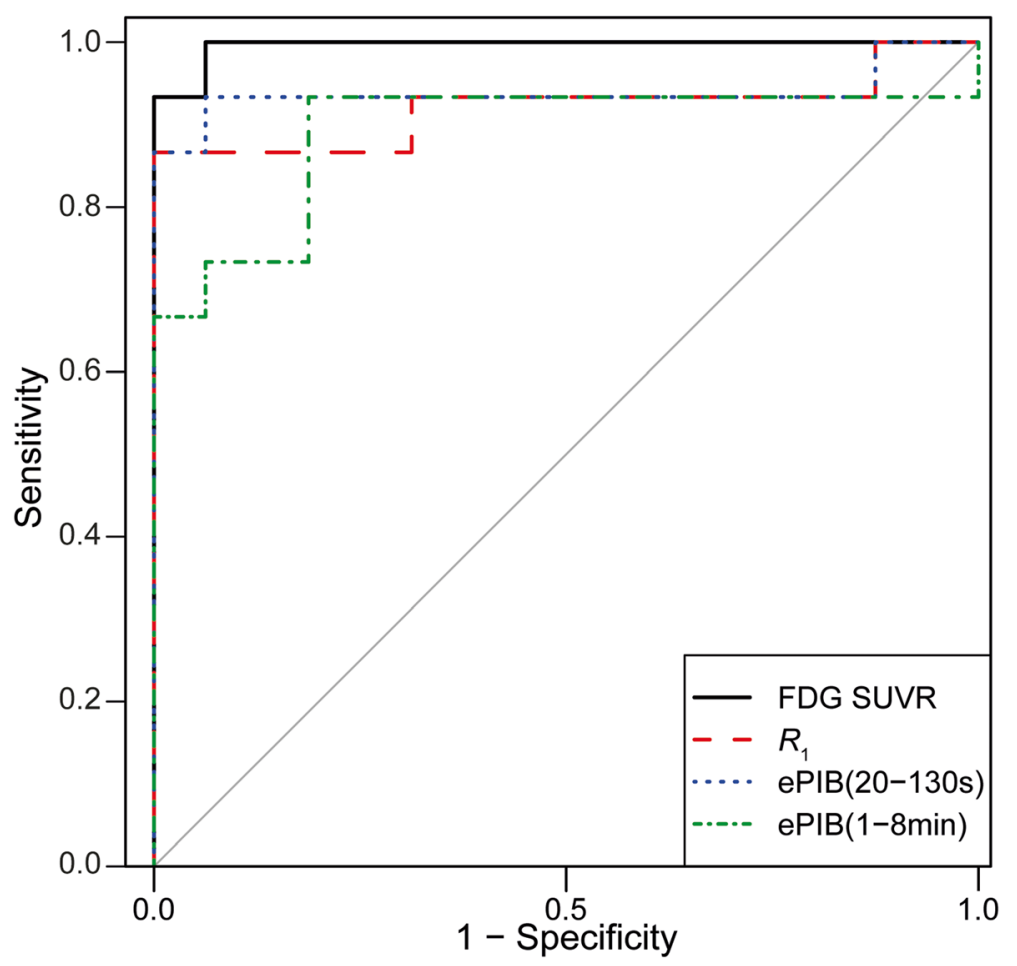

Fig. 4 ROC plots. ROC plot with the curves of FDG SUVR (solid line), $R_{7}$ (dashed line), ePIB (20-130 s) (dotted line), and ePIB (1-8 min) (dot dashed line)

Additionally, due to their high sensitivity and the fact that its ROC curve was not significantly different from those seen with FDG SUVR, rCBF images with an adjusted threshold are able to make a satisfactory distinction between groups for diagnostic purposes. The different thresholds found for each rCBF method suggest that, although they measure the same parameter, they do not yield the same results. This might be due to the fact that ePIB methods might be affected by some tracer binding already early after tracer administration, while $R_{1}$ is a measure of only flow relative to that of the cerebellum. Furthermore, it is important to mention that the same data was used to estimate the new threshold for classification of subjects and to estimate its performance, which might have led to overfitting. Therefore, the area under the ROC curve may provide a better performance estimate than the sensitivity and specificity results.

Although the results presented in the previous section show a good correlation between rCBF and FDG SUVR, these results should be taken with caution. PALZ pipeline (Additional file 2: Table S1) includes comparing the input image with a database of FDG scans of healthy volunteers, which might have declined the precision of the resulting rCBF scores. Therefore, even though the PALZ works for rCBF images given an adjusted threshold, the classification of the images could be improved by providing a tracerspecific database of HC subjects. Furthermore, the introduction of the $\mathrm{MCI}+$ and $\mathrm{MCI}-$ groups might have affected the results. This is due to the fact that PALZ is designed and validated only for the differentiation of $\mathrm{AD}$ patients from $\mathrm{HC}$, as mentioned above. But previous studies have shown that PALZ is more sensitive to disease progression than are clinical tests in the $\mathrm{MCI}$ group [2, 47]. For this reason, the MCI group was also included in this analysis. Moreover, there is still a need of longitudinal studies to assess changes in $R_{1}$ with the disease progression, since $R_{1}$ has shown not to be as sensitive as FDG in scenarios where small effect sizes are relevant. Furthermore, a limited number of subjects for setting the new threshold were used in this study; an increased number of patients could improve the accuracy of the threshold. In addition, the diagnosis of the patients was done based on the visual assessment of the images, which might have introduced some bias in the performance of PALZ, overestimating the performance of the tool.

\section{Conclusion}

The present study had the goal of using PIB-derived rCBF images as a surrogate for FDG-PET scans to classify subjects as AD patients or healthy individuals using the tool PALZ. The various methods of generating the rCBF method resulted in different $\mathrm{PET}_{\mathrm{SCORES}}$ for the images and, therefore, distinct correlations with FDG scores and thresholds for classifying the subjects. The results presented here suggest that $R_{1}$ parametric maps might be the 
best approach to generate rCBF images for diagnostic purposes provided that the threshold for classification is adjusted. Further research should focus on exploring how $\mathrm{PET}_{\text {SCORES }}$ correlate with disease progression in longitudinal studies.

\section{Additional files}

Additional file 1: An overview of the steps taken for analysing images. (DOCX $20 \mathrm{~kb}$ )

Additional file 2: Table S1. Mean \pm SD and range [minimummaximum] of all methods per group. (DOCX $14 \mathrm{~kb}$ )

\begin{abstract}
Abbreviations
AD: Alzheimer's disease; Aß: Amyloid- $\beta$; ePIB: Early-stage PIB; FDG: 2-[ $\left.{ }^{18} \mathrm{~F}\right]$ Fluoro-2-deoxy-D-glucose; FWHM: Full width and half maximum; HC: Healthy control; $k_{2}$ : Efflux parameter of the reference region; $\mathrm{MCl}$ : Mild cognitive impairment; MNI: Montreal Neurological Institute; MRI: Magnetic resonance imaging; NIA-AA: National Institute on Aging Alzheimer's Association; PALZ: PMOD Alzheimer's Discrimination Tool; PET: Positron emission tomography; PIB: ${ }^{11}$ C-labelled Pittsburgh Compound $\mathrm{B} ; R_{1}$ : Ratio of tracer influx relative to the reference region; rCBF: Regional cerebral blood flow; ROC: Receiver operating characteristic; SRTM: Simplified reference tissue model; SRTM2: Simplified reference tissue model 2; SUVR: Standardized uptake value ratio
\end{abstract}

\section{Acknowledgements}

The authors would like to thank the PMOD Technologies staff, specially Cyrill Burger, for the technical support. RB has received funding from the European Union's Horizon 2020 research and innovation programme under the Marie Skłodowska-Curie grant agreement No. 764458, which is not related to this work.

\section{Authors' contributions}

DEP and DVG contributed to the study design, image processing, data analysis, and writing and revision of the manuscript. FER and PPDD contributed to the coordination of the study, patient inclusion, data acquisition, and revision of the manuscript. JD contributed to the study design and revised the manuscript. BMJ contributed to the patient inclusion, data acquisition, and revision of the manuscript. RAJOD critically revised the manuscript. RB contributed to the study design, coordination of the study, and writing and revision of the manuscript. All authors read and approved the final manuscript.

\section{Funding}

Not applicable.

\section{Availability of data and materials}

The datasets generated and/or analysed during the current study are available with the corresponding author upon reasonable request.

\section{Ethics approval and consent to participate}

Ethical approval for the whole study, including the informed consent, was obtained from the Medical Ethical Committee of the UMCG (2014/320). All patients provided signed informed consent for participation in the study. Patients with a MMSE score higher than 18 were considered mentally competent to give informed consent. This cohort of subjects had a minimum MMSE score of 22; therefore, all subjects were considered mentally competent to give informed consent.

\section{Consent for publication}

All patients provided signed informed consent for participation in the study and for publication.

\section{Competing interests}

The authors declare that they have no competing interests.

\section{Author details}

${ }^{1}$ Department of Nuclear Medicine and Molecular Imaging, University Medical Center Groningen, University of Groningen, Hanzeplein 1, 9713, GZ, Groningen, The Netherlands. ${ }^{2}$ Department of Neurology, Alzheimer Centrum Groningen, University Medical Center Groningen, University of Groningen, Hanzeplein 1, 9713, GZ, Groningen, The Netherlands. ${ }^{3}$ Laboratory of Neurochemistry and Behaviour, Institute Born-Bunge, University of Antwerp, Universiteitsplein 1, 2610 Antwerpen, Belgium.

Received: 15 April 2019 Accepted: 20 June 2019

Published online: 04 July 2019

\section{References}

1. Nordberg A, Rinne JO, Kadir A, Långström B. The use of PET in Alzheimer disease. Nat Rev Neurol. 2010;6(2):78-87 Available from: https://doi.org/10. 1038/nrneurol.2009.217.

2. Morbelli S, Brugnolo A, Bossert I, Buschiazzo A, Frisoni GB, Galluzzi S, et al. Visual versus semi-quantitative analysis of 18F-FDG-PET in amnestic MCl: an European Alzheimer's Disease Consortium (EADC) project. J Alzheimer's Dis. 2015;44(3):815-26.

3. Reiman EM, Caselli RJ, Yun LS, Chen K, Bandy D, Minoshima S, et al. Preclinical evidence of Alzheimer's disease in persons homozygous for the $\varepsilon 4$ allele for apolipoprotein E. N Engl J Med. 1996;334(12):752-8. Available from: https://doi.org/10.1056/NEJM199603213341202.

4. de Leon MJ, Convit A, Wolf OT, Tarshish CY, DeSanti S, Rusinek H, et al. Prediction of cognitive decline in normal elderly subjects with 2[(18)F]fluoro-2-deoxy-D-glucose/positron-emission tomography (FDG/PET). Proc Natl Acad Sci U S A [Internet]. 2001;98(19):10966-71. Available from: https://doi.org/10.1073/pnas.191044198.

5. Small GW, Ercoli LM, Silverman DH, Huang SC, Komo S, Bookheimer SY, et al. Cerebral metabolic and cognitive decline in persons at genetic risk for Alzheimer's disease. Proc Natl Acad Sci U S A. 2000;97(11):6037-42. Available from: https://doi.org/10.1073/pnas.090106797.

6. Borczyskowski D, Wilke F, Martin B, Brenner W, Clausen M, Mester J, et al. Evaluation of a new expert system for fully automated detection of the Alzheimer's dementia pattern in FDG PET. Nucl Med Commun. 2006;27(9): 739-43

7. Herholz K, Salmon E, Perani D, Baron JC, Holthoff V, Frölich L, et al. Discrimination between Alzheimer dementia and controls by automated analysis of multicenter FDG PET. Neuroimage. 2002;17(1):302-16.

8. Teune L, Strijkert F, Renken R, Izaks G, Vries J, Segbers M, et al. The Alzheimer's disease-related glucose metabolic brain pattern. Curr Alzheimer Res. 2014;11(8):725-32. Available from: https://doi.org/10.2174/ 156720501108140910114230.

9. Pagani M, Giuliani A, Öberg J, Chincarini A, Morbelli S, Brugnolo A, et al. Predicting the transition from normal aging to Alzheimer's disease: a statistical mechanistic evaluation of FDG-PET data. Neuroimage. 2016;141: 282-90 Available from: https://doi.org/10.1016/j.neuroimage.2016.07.043.

10. Jueptner $M$, Weiller $C$. Review: does measurement of regional cerebral blood flow reflect synaptic activity? Implications for PET and fMRI. Neuroimage. 1995;2(2):148-56. Available from: https://doi.org/10.1006/nimg. 1995.1017.

11. Bélanger M, Allaman I, Magistretti PJJ. Brain energy metabolism: focus on astrocyte-neuron metabolic cooperation. Cell Metab. 2011;14(6):724-38 [cited 2011 Dec 13]. Available from: https://doi.org/10.1016/j.cmet.2011.08. 016.

12. Austin BP, Nair VA, Meier TB, Xu G, Rowley HA, Carlsson CM, et al. Effects of hypoperfusion in Alzheimer's disease. Adv Alzheimer's Dis. 2011;2:253-63.

13. Forsberg A, Engler $H$, Blomquist $G$, Långström B, Nordberg A. The use of PIB-PET as a dual pathological and functional biomarker in AD. Biochim Biophys Acta Mol Basis Dis. 2012;1822(3):380-5 Available from: https://doi. org/10.1016/j.bbadis.2011.11.006.

14. Hsiao IT, Huang CC, Hsieh CJ, Wey SP, Kung MP, Yen TC, et al. Perfusion-like template and standardized normalization-based brain image analysis using18F-florbetapir (AV-45/Amyvid) PET. Eur J Nucl Med Mol Imaging. 2013;40(6):908-20.

15. Hammes J, Leuwer I, Bischof GN, Drzezga A, van Eimeren T. Multimodal correlation of dynamic [18F]-AV-1451 perfusion PET and neuronal hypometabolism in [18F]-FDG PET. Eur J Nucl Med Mol Imaging. 2017; Available from: https://doi.org/10.1007/s00259-017-3840-z. 
16. Chen YJ, Rosario BL, Mowrey W, Laymon CM, Lu X, Lopez OL, et al. Relative 11C-PiB delivery as a proxy of relative CBF: quantitative evaluation using single-session 150-water and 11C-PiB PET. J Nucl Med. 2015;56(8):1199-205. Available from: https://doi.org/10.2967/jnumed.114.152405.

17. Meyer PT, Hellwig S, Amtage F, Rottenburger C, Sahm U, Reuland P, et al. Dual-biomarker imaging of regional cerebral amyloid load and neuronal activity in dementia with PET and 11C-labeled Pittsburgh compound B. J Nucl Med. 2011;52(3):393-400. Available from: https://doi.org/10.2967/ jnumed.110.083683.

18. Oliveira FPM, Moreira AP, de MA, Verdelho A, Xavier C, Barroca D, et al. Can 11C-PiB-PET relative delivery R1 or 11C-PiB-PET perfusion replace 18F-FDGPET in the assessment of brain neurodegeneration? J Alzheimers Dis. 2018; 65:89-97.

19. Valentina G, Silvia M, Marco P. Dual-phase amyloid PET: hitting two birds with one stone. Eur J Nucl Med Mol Imaging. 2016;43(7):1300-3 Available from: https://doi.org/10.1007/s00259-016-3393-6.

20. Teipel S, Drzezga A, Grothe MJ, Barthel H, Chételat G, Schuff N, et al Multimodal imaging in Alzheimer's disease: validity and usefulness for early detection. Lancet Neurol. 2015;14(10):1037-53.

21. Gjedde A, Aanerud J, Braendgaard H, Rodell AB. Blood-brain transfer of Pittsburgh compound B in humans. Front Aging Neurosci. 2013;5(NOV):1-9. Available from: https://doi.org/10.3389/fnagi.2013.00070

22. Peretti DE, Vállez García D, Reesink FE, van der Goot T, De Deyn PP, de Jong $\mathrm{BM}$, et al. Relative cerebral flow from dynamic PIB scans as an alternative for FDG scans in Alzheimer's disease PET studies. Ginsberg SD, editor. PLoS One. 2019;14(1):e0211000. Available from: https://doi.org/10.1371/journal. pone. 0211000

23. Rodriguez-Vieitez E, Carter SF, Chiotis K, Saint-Aubert L, Leuzy A, Scholl M, et al. Comparison of early-phase 11C-deuterium-L-deprenyl and 11C-Pittsburgh compound B PET for assessing brain perfusion in Alzheimer disease. J Nucl Med. 2016;57(7):1071-7. Available from: https://doi.org/10.2967/jnumed.115. 168732

24. Rostomian AH, Madison C, Rabinovici GD, Jagust WJ. Early 11C-PIB frames and 18F-FDG PET measures are comparable: a study validated in a cohort of AD and FTLD patients. J Nucl Med. 2011;52(2):173-9.

25. Tiepolt S, Hesse S, Patt M, Luthardt J, Schroeter ML, Hoffmann KT, et al. Early [18F]florbetaben and [11C]PiB PET images are a surrogate biomarker of neuronal injury in Alzheimer's disease. Eur J Nucl Med Mol Imaging. 2016; 43(9):1700-9 Available from: https://doi.org/10.1007/s00259-016-3353-1.

26. McKhann GM, Knopman DS, Chertkow H, Hyman BT, Jack CR, Kawas CH, et al. The diagnosis of dementia due to Alzheimer's disease: recommendations from the National Institute on Aging-Alzheimer's Association workgroups on diagnostic guidelines for Alzheimer's disease. Alzheimer's Dement. 2011; 7(3):263-9 Available from: https://doi.org/10.1016/j.jalz.2011.03.005.

27. Petersen R, Doody R, Kurz A, Al E. Current concepts in mild cognitive impairment. Arch Neurol. 2001;58(12):1985-92 Available from: https://doi. org/10.1001/archneur.58.12.1985.

28. Knopman DS, Haeberlein SB, Carrillo MC, Hendrix JA, Kerchner G, Margolin $\mathrm{R}$, et al. The National Institute on Aging and the Alzheimer's Association Research Framework for Alzheimer's disease: perspectives from the research roundtable. Alzheimer's Dement. 2018;14(4):563-75. Available from: https:// doi.org/10.1016/j.jalz.2018.03.002.

29. Boellaard R, O'Doherty MJ, Weber WA, Mottaghy FM, Lonsdale MN, Stroobants SG, et al. FDG PET and PET/CT: EANM procedure guidelines for tumour PET imaging: version 1.0. Eur J Nucl Med Mol Imaging. 2010;37(1): $181-200$.

30. Ashburner J, Friston KJ. Unified segmentation. Neuroimage. 2005;26(3):83951. Available from: https://doi.org/10.1016/j.neuroimage.2005.02.018.

31. Hammers A, Allom R, Koepp MJ, Free SL, Myers R, Lemieux L, et al. Threedimensional maximum probability atlas of the human brain, with particular reference to the temporal lobe. Hum Brain Mapp. 2003;19(4):224-47. Available from: https://doi.org/10.1002/hbm.10123.

32. Wu Y, Carson RE. Noise reduction in the simplified reference tissue model for neuroreceptor functional imaging. J Cereb Blood Flow Metab. 2002; 22(12):1440-52. Available from: https://doi.org/10.1097/01.WCB.0000033967. 83623.34 .

33. Yaqub M, Tolboom N, Boellaard R, van Berckel BNM, van Tilburg EW, Luurtsema G, et al. Simplified parametric methods for [11C]PIB studies. Neuroimage. 2008;42(1):76-86. Available from: https://doi.org/10.1016/j. neuroimage.2008.04.251.
34. Klunk WE, Engler H, Nordberg A, Wang Y, Blomqvist G, Holt DP, et al. Imaging brain amyloid in Alzheimer's disease with Pittsburgh Compound-B. Ann Neurol. 2004;55(3):306-19 Available from: https://doi.org/10.1002/ana. 20009.

35. Price JC, Klunk WE, Lopresti BJ, Lu X, Hoge JA, Ziolko SK, et al. Kinetic modeling of amyloid binding in humans using PET imaging and Pittsburgh Compound-B. J Cereb Blood Flow Metab. 2005;25(11):1528-47. Available from: https://doi.org/10.1038/sj.jcbfm.9600146.

36. Joachim CL, Morris JH, Selkoe DJ. Diffuse senile plaques occur commonly in the cerebellum in Alzheimer's disease. Am J Pathol. 1989;135(2):309-19. Available from: https://www.ncbi.nlm.nih.gov/pmc/articles/PMC1879919/.

37. Yamaguchi H, Hirai S, Morimatsu M, Shoji M, Nakazato Y. Diffuse type of senile plaques in the cerebellum of Alzheimer-type dementia demonstrated by $\beta$ protein immunostain. Acta Neuropathol. 1989;77(3):314-9.

38. Lammertsma AA, Hume SP. Simplified reference tissue model for PET receptor studies. Neuroimage. 1996;4(3):153-8. Available from: https://doi. org/10.1006/nimg.1996.0066

39. Holm S. A simple sequentially rejective multiple test procedure. Scand J Stat. 1979;6(2):65-70.

40. Krouwer JS. Why Bland-Altman plots should use $X$, not $(Y+X) / 2$ when $X$ is a reference method. Stat Med. 2008;27(5):778-80. Available from: https://doi. org/10.1002/sim.3086.

41. Youden WJ. Index for rating diagnostic tests. Cancer. 1950:32-5.

42. DeLong ER, DeLong DM, Clarke-Pearson DL. Comparing the areas under two or more correlated receiver operating characteristic curves: a nonparametric approach. Biometrics. 1988;44(3):837-45 Available from: https://www.ncbi.nlm.nih.gov/pubmed/3203132.

43. R Development Core Team. R: a language and environment for statistical computing. Vienna; 2017.

44. Giavarina D. Understanding Bland Altman analysis. Biochem Medica. 2015; 25(2):141-51 Available from: https://doi.org/10.11613/BM.2015.015.

45. Ho KM. Using linear regression to assess dose-dependent bias on a BlandAltman plot. J Emerg Crit Care Med. 2018;2:68

46. Jack CR, Bennett DA, Blennow K, Carrillo MC, Dunn B, Haeberlein SB, et al. NIA-AA Research Framework: toward a biological definition of Alzheimer's disease. Alzheimer's Dement. 2018;14(4):535-62. Available from: https://doi. org/10.1016/j.jalz.2018.02.018.

47. Herholz K, Westwood S, Haense C, Dunn G. Evaluation of a calibrated 18FFDG PET score as a biomarker for progression in Alzheimer disease and mild cognitive impairment. J Nucl Med. 2011;52(8):1218-26. Available from: https://doi.org/10.2967/jnumed.111.090902.

\section{Publisher's Note}

Springer Nature remains neutral with regard to jurisdictional claims in published maps and institutional affiliations.

\section{Submit your manuscript to a SpringerOpen ${ }^{\circ}$ journal and benefit from:}

- Convenient online submission

- Rigorous peer review

- Open access: articles freely available online

- High visibility within the field

- Retaining the copyright to your article

Submit your next manuscript at $>$ springeropen.com 